\title{
ONLINE CONTROL OF COMBINE REEL HEIGHT IN PRESENCE OF FARM ROUGHNESS USING AN ON-OFF CONTROLLER
}

\author{
Nadia ZENDEHDEL, Younes SHAMORADI
}

\begin{abstract}
Adjusting the harvesting combine reel height in presence of the farm rough surface reduces the harvest losses, prevents possible damage to the headland and increases gravel harvest. Regarding the importance of the issue, in this study, the dynamics of the reel height control system of the John Deere1055 combine was modeled and the controllability and observability of the obtained transfer function is determined in state space. After that, with the aim of cutting the stem from a suitable point, an on-off controller is designed to keep the reel height from the ground in a permitted range. At this stage, a reduced model system is used as an approximated system to design a controller. The designed controller is simulated in MATLAB. In this simulation, the roughness of the ground was considered as the control loop noise with the normal probability distribution function. The results confirm that the reel height change is kept in the specified range against the farm roughness. The laboratory sample was also constructed using an independent excitation circuit DC motor, an optical distance sensor, and a micro controller. The experimental test shows that the height control system responses to changes in surface height at an appropriate speed without any oscillation in range.
\end{abstract}

Keywords: combine headland, on-off controller, reel height, roughness of the farm

\section{INTRODUCTION}

Considering the strategic value of cereals such as wheat and barley, it is necessary to pay attention to reduce the harvest loss. Cutting stems from a proper height is an important factor in preventing cluster falling out, increasing the straw harvest and decreasing the amount of uncropped cluster at farm level. In the John Deere 1055 combine, the headland system settings, including the height of the reel from the ground, are adjusted by the operator outside the farm, before starting the harvest process. But the reel height is changed continuously in presence of farm roughness, during the harvesting process and combine movement. This not only affects the quality of cereal harvesting, but sometimes leads to a collision of reel into the ground and damaging it.

Studies on casualties during harvesting of some oilseeds and cereals show the combine headland have a significant role in harvesting quality [1]. One of the factors influencing the combine failure is the operation of the cutting machine [2]. The adaptation of these settings to the conditions of the products and the land characteristics significantly reduces the loss of harvest [3].

The study on the cutting headland has shown that $79.6 \%$ of the combine problems are related to reel and cutting blades [4]. In a local study, wheat harvest losses in Khorramabad were estimated at $21.5 \%$, such that $65 \%$ of the estimated loss is related to the natural casualties and $56.4 \%$ of it is return to the combine losses [5]. In Chaharmahal va Bakhtiari, the highest losses at harvesting stage were determined by John Deere combine 955 and 1055 in $6.8 \%$ of Omid wheat and $3.46 \%$ of Sardari wheat cultivar, respectively [6]. Due to the importance of improving the harvesting process, many researchers have been focusing on this issue in recent years. For example, a laboratory sample of the combine headland system was designed with the aim of minimizing the loss of rapeseed in harvesting stage [7].
In this sample model, the speed of the combine, the shear speed and the linear velocity of the reel are optimally determined. In order to prevent the excess losses of the John Deere 955 combine, using the concept of fuzzy control, the settings for controlling the reel round speed and the cutting speed of the cutting blade are optimized considering the speed of the combine while working in the field [8]. The presented system is introduced only to alert the driver. Additionally, the cutting height of the stem is not considered.

Regarding the fact that a suitable adjustment of combine head factors reduces wheat harvest loss as $50 \%$ in an experimental study [9], the effect of reel kinematic index factors, cutting height, vertical distance of the reel from the shoulder cut and the horizontal distance of the carousel from the shoulder on head loss were identified, respectively. Then, based on the results, a neuro-fuzzy controller was designed in simulink and used to determine the relevant variables.

In the study of [10], with the help of fuzzy logic, the automated adjustment of factors which affect the performance of the end of the John Deere 955 combine has been studied and has not been addressed to harvesting stages.

In our country, mechanized harvesting of cereals is often done by combines that their headland adjustments should be done intuitively by operator, out of the field and before the start of the process. Due to the ruggedness of the farm's surface, during the harvest, the height of the carousel changes from the surface of the earth and some adjustments should be done.

In this research, with the aim of controlling the height of the carousel and clipping of the cluster stem from the appropriate height, a controller is designed and the control system is simulated in the Simulink environment. The proposed control system samples the vertical height of the carousel using some sensors and compares it with a reference height. If the error exceeds the allowable tolerance, the control loop moves reel shaft on the headland to maintain the carousel height changes in a stable and acceptable tolerance. 
To this "end" an "on-off" controller controls the peripheral rotation of a DC motor. This rotary motion is converted to the linear motion by power screw to drive the carriage shaft to the optimum level up or down.

\section{MATERIALS AND METHODS}

In the proposed control system, the required tensile force which is necessary move the reel system is prepared by the kinetic energy of a DC engine. The force is applied to the reel after changing from rotary to tensile. Therefore, the rotational movement of the engine should be controlled in response to the change in the height of the combine head, which is measured by a sensor. Since the reel height should be maintained in a given range, an on-off controller is suitable to be design.

\subsection{Research Theory \\ 2.1.1 The Independent Excitation DC Motor Dynamical Behaviour}

The engine is a machine that is responsible for converting electrical energy into mechanical energy. In this study, the required motional energy is provided by the mechanical energy of an independent excitation DC motor which is controlled by the armature voltage. With the assumption of the constant current of the armature circuit $\left(i_{f}\right)$, the linear model of rotor torque $(T)$ is calculated from Eq. (1). In this relation $(k)$ is the conversion coefficient.

$$
T=k i_{f}
$$

Using the Newton's second law, the dynamic equation of engine angular rotation is obtained in accordance with Eq. (2).

$J \frac{\mathrm{d} \theta^{2}(t)}{\mathrm{d} t^{2}}=k i_{f}(t)-f \frac{\mathrm{d} \theta(t)}{\mathrm{d} t}$

$\theta$ represents the engine angular rotation. $J$ and $f$ respectively indicate shaft inertia and friction. In addition, the voltage of the input loop of the excitation field is also determined according to Eq. (3).

$$
e_{f}(t)=R_{f} i_{f}+L_{f} \frac{\mathrm{d} i_{f}(t)}{\mathrm{d} t}
$$

$R_{f}$ and $L_{f}$ indicate the resistivity and inductance of the armature circuit, $i_{f}$ and $e_{f}$ respectively, the excitation field current and voltage. The transfer function of the motor with the armature voltage as its input and the rotor rotation as the output variable is determined using the Laplace transform of relations (2) and (3). After linearization, the transfer function is calculated as it is formulated by Eq. (4). In Eq. (4), $N$ shows the number of armature windings.

$$
G(s)=\frac{Q(t)}{E_{f}(t)}=\frac{\frac{N}{\pi}}{s\left[\left(J L_{f}\right) s^{2}+\left(R_{f} J+L_{f} f\right) s+\left(R_{f} f\right)\right]}
$$

Regarding the angular rotational relationship and linear displacement, the transfer function of the motor is changed as Eq. (5).

$$
G(s)=\frac{x(s)}{E_{f}(s)}=\frac{\frac{N r}{\pi}}{s\left[\left(J L_{f}\right) s^{2}+\left(R_{f} J+L_{f} f\right) s+\left(R_{f} f\right)\right]}
$$

The values of coefficients in Eq. (5) are set based on the experimental characteristics of an independent excitation motor with a nominal voltage of $24 \mathrm{~V}$ and a nominal speed of $20 \mathrm{rpm}$. The factors obtained in the laboratory are given in Tab. 1. The mass of the rotor shaft in presence of power screw is considered $10 \mathrm{~kg}$. In calculating these parameters, the John Deere 1055 combine headland angle is considered 45 degrees and the weight of the carriage is 20 kilograms. From the mechanical point of view, due to the weight of the moving structure and its distance from the center of gravity, two inertial and frictional forces are presented as two opposing forces. The effect of these two forces can be minimized by using a ball bearing or power screw, and the speed of the system is increased. With this in mind, the coefficient of friction movement is considered 0.64.

Table 1 Parameters of DC motor and combine headland
\begin{tabular}{|c|c|c|c|c|c|c|}
\hline$J\left(\mathrm{~kg} \cdot \mathrm{m}^{2}\right)$ & $f$ & $N$ & $r(\mathrm{~m})$ & $L_{f}(\mathrm{mH})$ & $R_{f}(\mathrm{~m} \Omega)$ & parameter \\
\hline 19.27 & 0.64 & 2000 & 0.02 & 27.5 & 164 & value \\
\hline
\end{tabular}

With respect to the values of engine parameters and reel, the engine transfer function is obtained as Eq. (6).

$$
G(s)=\frac{x(s)}{E_{f}(s)}=\frac{12.73}{0.53 s^{3}+3.18 s^{2}+0.11 s}=\frac{24}{s^{3}+6 s^{2}+0.21 s}(6)
$$

\subsubsection{Investigating the Features of Open Loop and Closed Loop Systems}

According to Eq. (6), system is type one and marginal stable. In other words, the system will have a bounded output in response to a bounded input. Figs. 1 and 2 indicate the step response of the closed loop and open loop system, respectively.

The closed-loop system shows a stable behavior, while the open-loop step response system has incremental behavior. Based on state space studies, the system is controllable and observable. Therefore, it is possible to use the on-off controller to keep the system's output changes in a desirable range. 


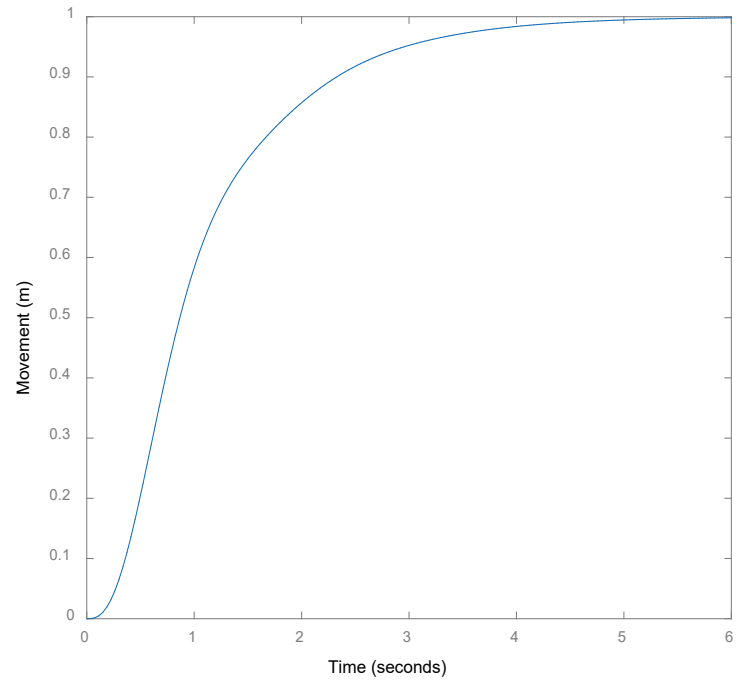

Figure 1 Closed-loop system step response

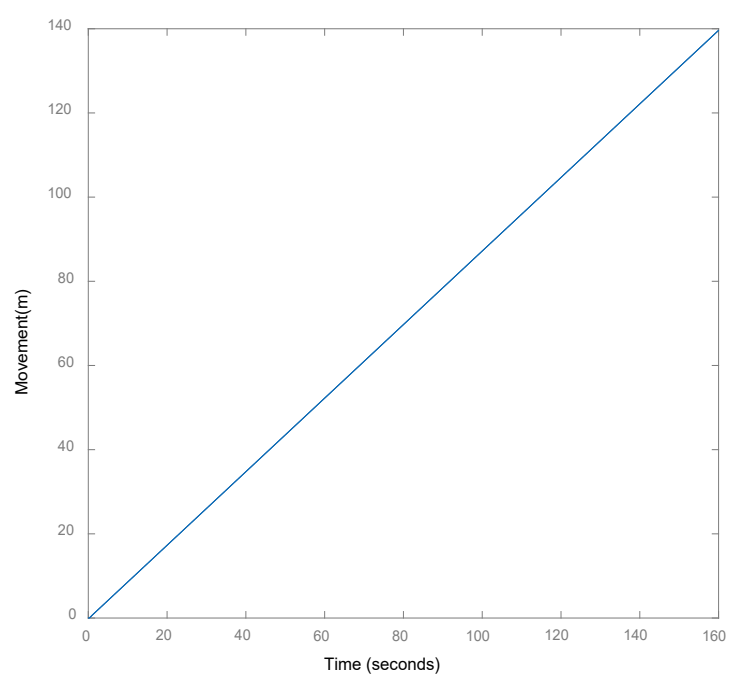

Figure 2 Open-loop system step response

\subsubsection{Controlling the Reel Height with the Aim of Reducing Harvest Losses against Surface Roughness}

In this section, controlling the reel height is discussed and an on-off controller is designed. To this end, the height change of the farm is monitored continuously during the combine movement. The controller drives a motor to change the reel height based on the measurements.

On-off controller is a non-linear and discrete controller that controls the duty cycle of the hysteresis relay operation. The system secures the closed-loop system output in terms of a reference point, within a permitted range of changes [11].

\subsubsection{Model Reduction}

Designing an on-off controller for a system of type 2 and above is a nonlinear, complex problem, with a heavy computing need. Since the reel height control system is type 3 , it is necessary to approximate it by a model reduction system which is type 1 . The constant gain $(k)$ and the time constant $(T)$ of a first order system transfer function
$G(s)=\frac{K}{1+T_{S}}$ are calculated respectively, by relations (7) and (8).

$S_{1}(\infty)=\lim _{s \rightarrow 0} s \times \frac{1}{s} \times \frac{K}{1+T s}=k$

$S_{1}(T)=0.632 k$

Based on the step response of the combine reel control system shown in Fig. 1, the reduced model is obtained by relation (9).

$G(s)=\frac{24}{s^{3}+4.6 s^{2}+27.51 s+24} \equiv \frac{1}{1+1.09 s}$

Fig. 3 shows the step response of the original and approximated system. In this figure, the continuous line diagram is related to the step response of the reel control system and the dotted line diagram is the step response of the approximated system.

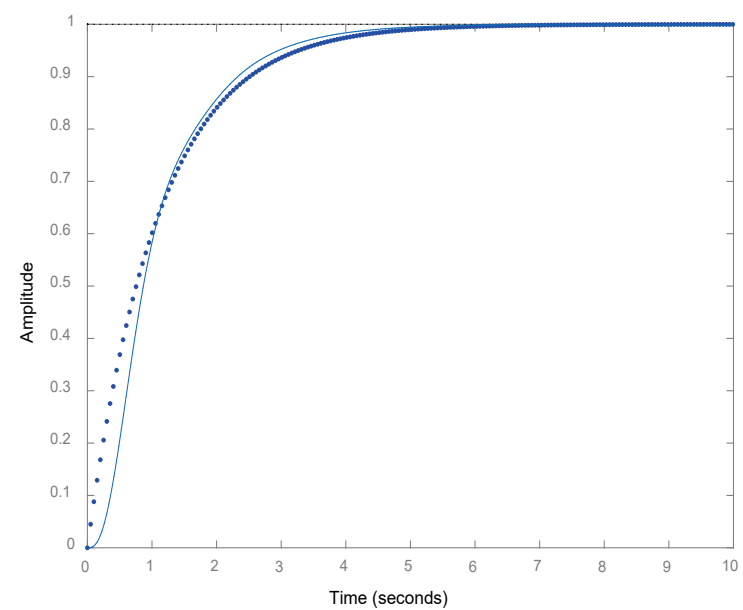

Figure 3 Step response of the reel height controlled system and approximated system

As it can be shown, the step response of the system and its approximation in the operating interval is the same.

\subsubsection{On-off Controller Design}

Based on the designing theory of an on-off controller, control input is determined by relation (10), using parameters such as the reference point and the allowable range of output variations, as well as the existence delay in relay operation.

$$
p=\frac{x_{1} x_{2}\left(e^{\frac{T_{0}}{T}}-1\right)}{K\left(x_{1} e^{\frac{T_{0}}{T}}-x_{2}\right)}
$$


The parameters $x_{2}$ and $x_{1}$ are the lower and upper bound of the reel height change interval. The parameter $p$ is the voltage should be applied as input to motor. $T_{0}$ is also the operating time of the relay. Considering the relay operation time as 0.15 seconds, the optimum height as for cutting the stems of grain $0.75 \mathrm{~m}$ and an acceptable error as $0.05 \mathrm{~m}$, the armature voltage is obtained 23.5 volts.

\section{RESULTS AND DISCUSSION}

\subsection{Simulation and Numerical Results}

The presented on-off controller is applied on the combine reel height control system in the simulink environment and its performance is tested in the presence of disturbances caused by farm roughness. In this section, the roughness of the earth is determined by a random function with a Gaussian probability distribution function with zero mean and the variance of 10 . Fig. 4 shows the changes in moving combine reel because of the surface roughness over a period of 60 seconds.

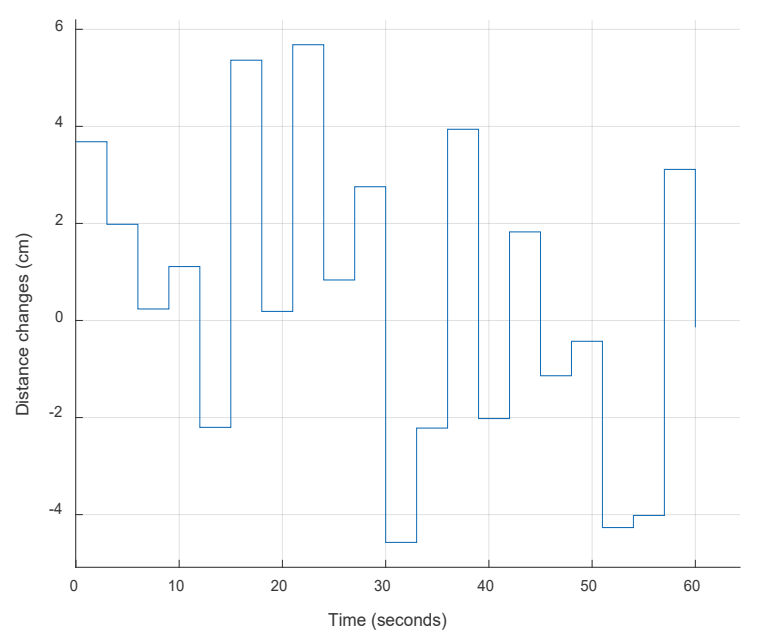

Figure 4 Changes in moving combine headland due to the surface roughness

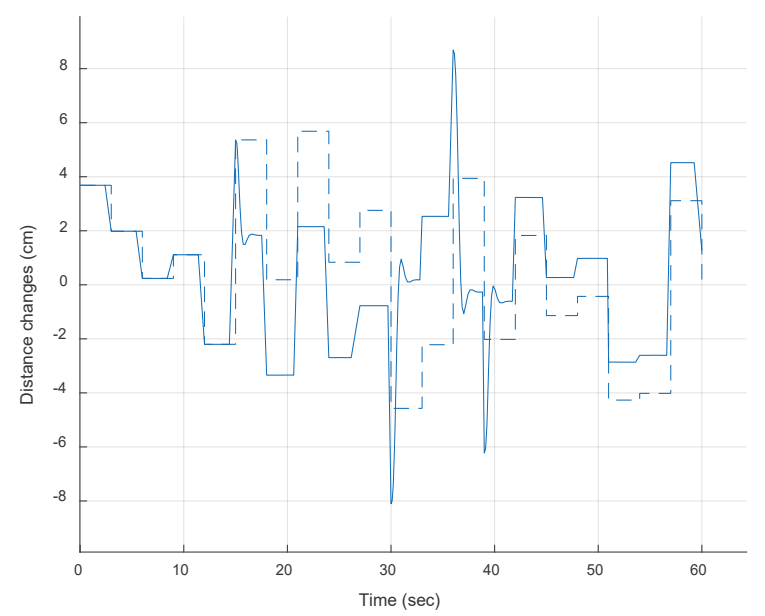

Figure 5 Controlled reel height changes (continuous line diagram), Combine head height changes because of farm roughness (doted diagram)

Considering the suitable height for cutting the stem of the wheat cluster as $0.75 \mathrm{~m}$ with tolerance of $0.05 \mathrm{~m}$, the permitted height for the reel location is between 0.7 and 0.8 meters. As shown in Fig. 5, the controller, in response to the farm roughness, applies the voltage to the engine armature with an adjusted left / right direction and maintains the reel distance to the ground level in the desired range.

It is evident in Fig. 5 that when the moving combine passes above a tall roughness and the reel height changes more than $5 \mathrm{~cm}$, the right-turned relay is activated and the voltage applied to the motor. So, the reel is returned to the permitted range.

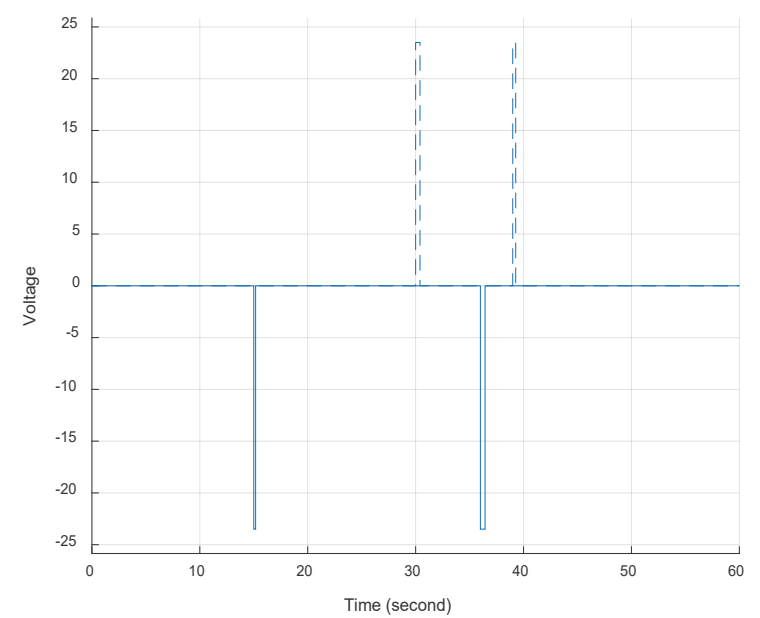

Figure 6 Right-turned relay operation (continuous line) and left-turned relay operation (dotted)

Fig. 6 shows the operation of the right and left-turned relays.

\subsection{Performance of the On-Off Reel Height Controller}

In the following, the performance of the reel height control system is discussed at time 15 seconds and 30 seconds. At 15 seconds, the combine is placed on a roughness, and the reel height rises as much as $5.36 \mathrm{~cm}$ from the base level. As a result of this change, the reel will also be at $80.36 \mathrm{~cm}$ above the base. This height is out of the acceptable tolerance which is defined for the on-off controller. Therefore, as shown in Fig. 6, the right -turned relay is actuated and the voltage is applied to armature. The height change shown in Figure 5 (continuous line) indicates that the reel moves to reduce the height and reel enters the permitted range.

Due to the rapid response of the motor after about 0.6 seconds, the reel enters the permissible height and the relay is turned off (Fig. 6). But due to the kinetic inertia of the motor, the reel moves downward after the relay is turned off for 1.38 seconds. Finally, the reel stops at $1.9 \mathrm{~cm}$ above the base level at 16.83 seconds.

On the other hand, analyzing the change of reel height at the moment of 30 seconds indicates that due to the roughness of the ground at that moment, the height of the headland decreases $4.6 \mathrm{~cm}$. On the contrary, this height drop is also imposed on the reel and it is placed at $66.9 \mathrm{~cm}$. At this time, the left-turned relay is activated at 0.4 second (Fig. 6), and 
the voltage is applied to drive motor and return the reel to the permitted height interval. As shown in Fig. 6, the reel movement continues 1.9 seconds to reach a height $1.3 \mathrm{~cm}$ above the base. After that, the engine is placed in steady state mode.

\subsection{On-Off Height Controller Simulation}

The proposed control system is simulated in MATLAB. In this way, the operator can define the situation of the farm surface roughness and the allowable combine reel position respect to suitable stem cutting point. In the simulation, the position of the reel height changes in the block is applicable to the control loop through "Distance change" block. Additionally, the acceptable tolerance of the stem cutting point can be defined through "R-relay" and "L-relay" blocks. This section can be set by the operator according to the type of the grains. The "Transfer function" block contains the model reel height control system consisting DC motor and a part of combine head. This block is modeled completely depends on the type of combine and used motor. If necessary, its parameters can be adjusted in accordance with the combine. Finally, to show the simulation results the "Display1", "Display2" and "Display3" blocks are used. They respectively show the surface roughness sensor measurement, relay on-off state, and reel height compared to the reference level. Fig. 7 illustrates the control block diagram.

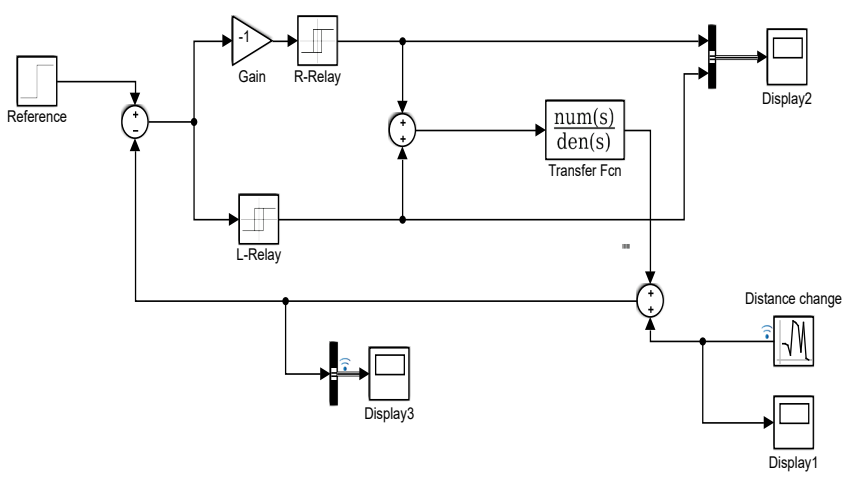

Figure 7 Simulation block diagram

The proposed control algorithm has outstanding features. It is based on the analytical control method and use the linear control theory. The designed controller is not expert based and it is independent of verbal rules. Therefore, it is free from human error. Additionally, the mentioned method is independent from the type of grains, land, and any experiences associated with them. So, it is easily usable and generalized in the process of harvesting a variety of grains or types of farms with different surfaces. Another important advantage of this controller is the high speed of response to the changing height of the moving combine head. The used relies capable to switch in response to the farm roughness with respect the speed of the combine (approx. $20 \mathrm{~km} / \mathrm{h}$ ). Using a gearbox and a power screw also makes it possible for the control system to change the reel position not only in the John Deere 1055 with a $20 \mathrm{~kg}$ reel weight, but also in other similar machines up to $50 \mathrm{~kg}$ weight. The proposed control method enables the setting parameter feature for the operators and it is guarantee the flexibility factor of the controller.

\section{CONCLUSION}

In this study, in order to guarantee the cutting of grain stems from a specific height with constant tolerance, an onoff controller was designed and used as a closed loop control method. Typically, a study was conducted on John Deere 1055 harvesting combine. Suitable height for cutting is considered as $0.75 \mathrm{~m}$ with an acceptable tolerance of $0.05 \mathrm{~m}$. The controlled system is simulated in MATLAB. The results show a fast and appropriate response of the reel height control system against the farm roughness considered as a noise signal in simulation.

The controller acts human error-free and independent from the operator's experience. In addition, the control method can adapt with various types of harvest combine, grains and different levels of agricultural land.

\section{REFERENCES}

[1] Shahab-Zadeh, M. M. (2005). Design, construction and evaluation canola harvest by helping the separator. Doctoral dissertation, Thesis, Faculty of Agriculture, Shiraz University. (In Farsi)).

[2] Jalali, A. \& Abdi, R. (2014). The Effect of Ground Speed, Reel Rotational Speed and Reel Height in Harvester Losses. Journal of Agriculture and Sustainability, 5(2).

[3] Campbell, W. P. \& Alswager, S. S. (2003). Adjusting equipment now can alleviate harvest losses. Biological Systems Engineering.(402), 2472-3030.

[4] Quick, G. R. \& Mills, W. M. (1978). High Capacity NarrowPitch Soybean Cutterbar. Transactions of the ASAE, 21(2), 277-0280. https://doi.org/10.13031/2013.35289

[5] Rahmati, M., H. Rozdari, A. M., Ezadi, M., \& Yousefian, S. H. (2014). Evaluation and comparison of wheat harvest losses for two common combines in Khorramabad Township. Journal of Researches in Mechanics of Agricultural Machinery, 3(1).

[6] Mirasi, A., Asoodar, M. A., Samadi, M., \& Kamran, E. (2014). The Evaluation of wheat losses harvesting in two conventional combine (John Deere 1165, 955) in Iran. International Journal of Advanced Biological and Biomedical Research, 2(5), 14171425.

[7] Soleimani, M. \& Kasraei, M. (2012). Optimum Adjustments of Cereal Combine Harvester Platform for Canola Harvesting by Using of a Simulated Platform. Journal of Agricultural Machinery.

[8] Javidi, M. (2005). Simulation of a control and alarm system for the harvesting combine. Master thesis. (In Farsi).

[9] Zareei, S. \& Abdollahpour, S. (2016). Simulation of neurofuzzy model for optimization of combine header setting. Journal of Agricultural Machinery, 6(2), 406-416.

[10] Lashgari, M., Mobli, H., Omid, M., Alimardani, R., Mohtasebi, S., \& Hesamifard, R. (2008). Implementation and Evaluation of a Fuzzy Logic Controller for the Automatic Settings of a Combine Harvester. Journal of Agricultural Engineering Research, 9(3), 75-88.

[11] Merikh-Baiat, F. (2009). Modelling and industrial control. (In Farsi). 
Authors' contacts:

Nadia ZENDEHDEL

Corresponding author

Faculty of Electrical and Computer Engineering,

Department of Electrical Engineering,

Quchan University of Technology,

Quchan, Iran

nadia.zendehdel@gmail.com

Younes SHAMORADI

Faculty of Electrical and Computer Engineering,

Department of Electrical Engineering,

Quchan University of Technology,

Quchan, Iran 